\title{
As aplicações móveis no ensino da História e no desenvolvimento da consciência histórica
}

\author{
The mobile applications in History teaching and in the \\ development of historical consciousness
}

Helena Isabel Almeida Vieira*

Cristiano Augusto Fernandes Ferreira ${ }^{* *}$

\section{Resumo}

As novas tecnologias estão em constante evolução, alterando o nosso modo de viver. A educação e o desenvolvimento da consciência histórica não podem ser alheios e devem acompanhar os seus avanços. Neste trabalho exploramos o mobile learning, ainda pouco explorado e enraizado no ensino em geral, e no ensino da história em particular. Com base em dois estudos de caso - o uso da aplicação "VêsTudo" e a atividade "O Porto na Nuvem", pretende-se mostrar como as aplicações móveis podem ser pontos de partida para o ensino da História, para o conhecimento do património local e para o desenvolvimento da consciência histórica. Os estudos de caso desenvolvidos evidenciaram que os alunos estão recetivos a metodologias de trabalho com dispositivos e apps móveis, considerando-as motivadoras e ferramentas importantes de exploração e avaliação de conhecimentos.

Palavras-chave: mobile learning; ensino da História; consciência histórica.

\section{Abstract}

New technologies are constantly evolving, changing our way of life. The education and the development of historical consciousness cannot be extraneous and should follow their progress. In this paper we explore mobile learning, still little explored and rooted in education in general, and in particular in History teaching. Based on two case studies the use of the application "VêsTudo" and the activity "O Porto na Nuvem," this paper aims to show how mobile applications can be starting points for History teaching, for the knowledge of local heritage and the development of historical consciousness. Case studies have shown that students are receptive to working methods with mobile devices and apps considering them motivating and important as exploration tools and ways of knowledge assessment.

Keywords: mobile learning; History teaching; historical consciousness.

\footnotetext{
* Doutora em História. Centro de Investigação Transdisciplinar Cultura, Espaço e Memória (CITCEM) e Faculdade de Letras da Universidade do Porto, Portugal. vieira.helenaisabel@gmail.com

** Mestre em Ensino da História e Geografia no $3^{\circ}$ Ciclo do Ensino Básico e Ensino Secundário. Centro de Investigação Transdisciplinar Cultura, Espaço e Memória (CITCEM) e Faculdade de Letras da Universidade do Porto, Portugal. cristianoferreira_88@hotmail.com
} 
$\mathrm{Na}$ atualidade, quando olhamos ao nosso redor, verificamos que as novas tecnologias fazem parte das nossas rotinas em todos os momentos. A utilização de diversos dispositivos retira o máximo partido das suas potencialidades, com o objetivo de facilitar o nosso dia a dia.

Sabendo que as novas tecnologias são um processo em constante evolução, torna-se "difícil encontrar uma aceção satisfatória para esta expressão [já que] o que hoje é novo, amanhã já não o é” (Guerreiro, 2013, p.11).

Este trabalho, realizado no âmbito do estudo do uso de novas tecnologias no ensino da História e no desenvolvimento da consciência histórica dos alunos, procura explorar um novo conceito em educação, o mobile learning, que vem do uso de dispositivos móveis, nomeadamente smartphones e tablets, em contexto educativo, assim como ilustrar possíveis formas de sua potencialização. Para tal, baseia-se em dois estudos de caso aplicados em Portugal em contextos distintos, para os quais foram propositadamente criadas duas aplicações móveis, desenhadas para funcionar em dispositivos com o sistema operativo Android: uma denominada "VêsTudo: visita à Rota do Românico" e outra "O Porto na Nuvem", com o objetivo de explorar o património local recorrendo a estratégias de mobile learning e, paralelamente, desenvolver a consciência histórica dos alunos.

Os resultados apresentados ao longo deste artigo procurarão responder a questões como: "Poderão os dispositivos móveis contribuir para o desenvolvimento da consciência histórica?"; "Serão as aplicações móveis úteis para dinamizar visitas de estudo?"; "Serão os questionários online um bom método de recolha/avaliação de informação?”.

\section{BREVE DESCRIÇÃO METODOLÓGICA}

Com vista a dar resposta às questões levantadas, servimo-nos de literatura de referência nacional e internacional baseada em estudos sobre o mobile learning e sobre a sua aplicação num contexto específico - o ensino da História e o desenvolvimento da consciência histórica dos alunos.

A investigação assentou, essencialmente, na análise de dois estudos de caso: um primeiro em espaço de educação formal mas em contexto exterior à sala de aula, realizado no âmbito de uma visita de estudo, realizada em março do ano letivo de 2014/2015, na Escola Secundária de Paredes, e no âmbito da 
formação inicial de professores da Universidade do Porto, e um segundo em contexto de educação não formal, inserido no programa "Universidade Júnior" da Universidade do Porto, que se realiza anualmente, no mês de julho, e que pode ser considerado como um programa de férias.

Para estas experiências didáticas foram construídas duas aplicações móveis específicas tendo em conta que se destinavam a públicos-alvo diferentes: a experiência de aprendizagem centrada na aplicação "VêsTudo: visita à Rota do Românico" realizou-se com alunos do $10^{\circ}$ ano (15-16 anos), no âmbito de visita de estudo, enquanto a experiência de aprendizagem centrada na aplicação "O Porto na Nuvem" realizou-se com alunos do $5^{\circ}$ e $6^{\circ}$ anos (10-12 anos), no âmbito do programa Universidade Júnior, da Universidade do Porto.

Ambas as atividades começaram por ser previamente planeadas tendo em conta os objetivos didáticos que se esperava alcançar. Procedeu-se, depois, à construção das aplicações móveis, tendo em consideração que estas deveriam ter conteúdo suscetível de promover a aquisição e o desenvolvimento de conhecimentos históricos, mas também desenvolver a própria consciência histórica dos alunos. Esses conteúdos foram ainda complementados com atividades de avaliação formativa a fim de verificar se os objetivos didáticos pretendidos eram alcançados.

As atividades foram observadas por professores e monitores e foram ainda alvo de uma avaliação por parte dos próprios alunos que as realizaram, mediante inquéritos online, com o intuito de percecionar a sua opinião relativamente a experiências com recurso a mobile learning.

\section{O MOBILE LEARNING NO ENSINO DA HISTÓRIA E NO DESENVOLVIMENTO DA CONSCIÊNCIA HISTÓRICA}

Com o desenvolvimento e proliferação de novas tecnologias, muitas investigações têm sido realizadas sobre a forma como podem elas servir à educação. Atualmente, dispositivos móveis como smartphones e tablets têm provocado novas formas de interação social e um esbatimento das barreiras espaciais. $\mathrm{O}$ facto de estarmos contactáveis a qualquer hora e lugar e de podermos instantaneamente aceder a uma vasta rede de informação online veio alterar a sociedade e reconfigurar as nossas relações sociais. Por esse motivo, tais dispositivos têm 
sido estudados não só como tecnologia, mas também como artefacto social e, mais recentemente, como ferramenta pedagógica e didática.

A proliferação das tecnologias móveis e a sua aceitação por professores e estudantes podem abrir novas perspetivas pedagógicas. Os smartphones apresentam como grande vantagem a capacidade de oferecer o que Metcalf (2002) designa por “stolen moments for learning", enquanto se espera numa paragem ou se viaja de autocarro ou comboio.

São vários os estudos realizados nos últimos anos sobre experiências de mobile learning em contexto formal e informal que reportam resultados positivos, bem como a aceitação das tecnologias móveis por parte dos alunos, tais como; Kukulska-Hulme (2005) e Sharples (2005).

Em Portugal, no ensino em geral e no ensino da História em particular, as aplicações móveis ainda não são totalmente exploradas, mas algumas experiências e estudos pioneiros têm vindo a realizar-se, demonstrando que existe uma consciência e preocupação com o seu uso e exploração como ferramenta de ensino e de aprendizagem. De entre elas, destacam-se os trabalhos de Moura (2010), Trindade (2014) e Ferreira (2015).

A sociedade atual encontra-se indiscutivelmente marcada pelas novas tecnologias. Como tal, a Escola e os professores não podem alhear-se dessa realidade e devem integrar as novas tecnologias nas suas práticas de ensino, com o intuito não só de tornar as aulas mais atrativas para os alunos, mas sobretudo de fazê-lo tendo em vista a preparação dos estudantes, profundamente habituados às tecnologias que os rodeiam, para os desafios do mundo atual, incentivando-os a desenvolver competências de comunicação, pesquisa, seleção e avaliação crítica da informação que lhes surge diariamente.

As tecnologias móveis ao serviço do ensino da História e do desenvolvimento de uma verdadeira consciência Histórica, aqueles que se tornam objeto de estudo neste trabalho, não significam falar apenas em smartphones ou tablets, implicam também criar mentes móveis, em que a partir de um qualquer dispositivo um aluno possa alargar os seus conhecimentos, independentemente do espaço físico onde se encontre.

Entende-se por mobile learning o processo de aprendizagem que ocorre apoiado pelo uso de dispositivos móveis, tendo como característica fundamental a portabilidade dos dispositivos e a mobilidade dos sujeitos, que podem 
estar física e geograficamente distantes uns dos outros ou em espaços físicos formais de educação, como a sala de aula.

Neste estudo, apontamos ainda o mobile learning como um processo igualmente capaz de potencializar a educação da História num contexto de educação formal, mas fora do espaço tradicional de sala de aula, em contexto de visitas de estudo, acreditando que a aprendizagem da História e o desenvolvimento da consciência histórica não se restringem apenas ao espaço de sala de aula, mas podem ser concretizados em qualquer lugar, desde que devidamente pensados e executados em termos didáticos.

Apesar de cada vez mais se defender e praticar a interdisciplinaridade, no sistema de ensino português, básico e secundário, é à disciplina de História que tem cabido o principal papel na formação de uma consciência histórica, na construção de valores culturais e sociais e na integração desses conhecimentos na vida de cada um dos jovens. Esta ocorre em diferentes contextos de aprendizagem, e não exclusivamente na sala de aula, porque aprender em História não é apenas reproduzir conteúdos previamente decorados, não se limita à enumeração de datas e acontecimentos, nem à narração de histórias de figuras marcantes. O desenvolvimento da cognição histórica assenta na forma como professores e alunos abordam conceitos específicos da disciplina, aplicando-os depois no seu próprio quotidiano. Nesse sentido, Isabel Barca refere que entre os autores que exploram a construção da consciência histórica pelos jovens destacam-se os que assentam a pesquisa na questão essencial de ancorar o conhecimento de uma história substantiva em ideias de segunda ordem que permitam usar esse conhecimento para uma análise crítica do mundo atual, como consciência histórica avançada e não como conhecimento inerte (Barca, 2008).

\section{"VêsTudo" E “O Porto na Nuvem" - aplicações MÓVEIS NO ENSINO DA HISTÓRIA E NO DESENVOLVIMENTO DA CONSCIÊNCIA HISTÓRICA}

Conforme foi mencionado anteriormente, para esta investigação foram criadas duas aplicações móveis, desenhadas para funcionar em dispositivos com sistema operativo Android, uma denominada "VêsTudo: visita à Rota do Românico" e outra "O Porto na Nuvem", com o objetivo de explorar o património local de uma forma diferente da tradicional, despertando o interesse e 
a motivação dos alunos em observar a herança que os rodeia, o "legado ... recebido dos ... antepassados” (Moreira, 2006, p.127), recuperado, reabilitado e conservado até aos nossos dias, tendo em vista desenvolver a consciência histórica dos alunos a partir de algo concreto - o património histórico e cultural local.

As duas aplicações assentam em princípios de construção e de visualização comuns, privilegiando a funcionalidade em detrimento do aspeto. Olhando para as Figuras 1 e 2, podemos verificar a simplicidade dos layouts, utilizando backgrounds simples e botões de acesso a cada menu de grandes dimensões, destacando as funções a que se destinam, ou seja, num primeiro momento os botões destinados a fornecer informação relativa ao património em visita (menu Monumentos e menu Explora) e a avaliar os conhecimentos adquiridos na atividade (menus Guião de exploração e Quiz).

Figura 1 - App "VêsTudo"

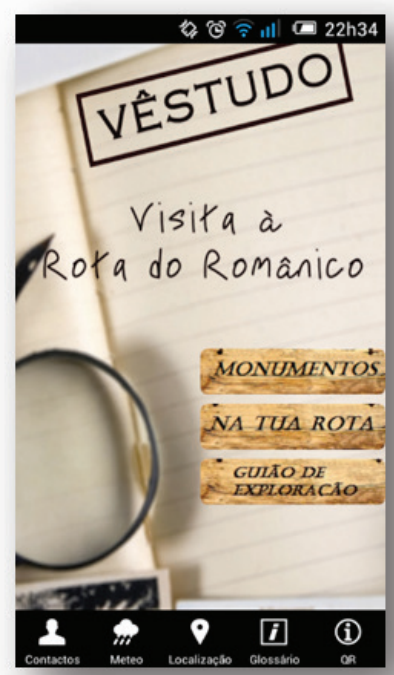

Figura 2 - App “O Porto na Nuvem”

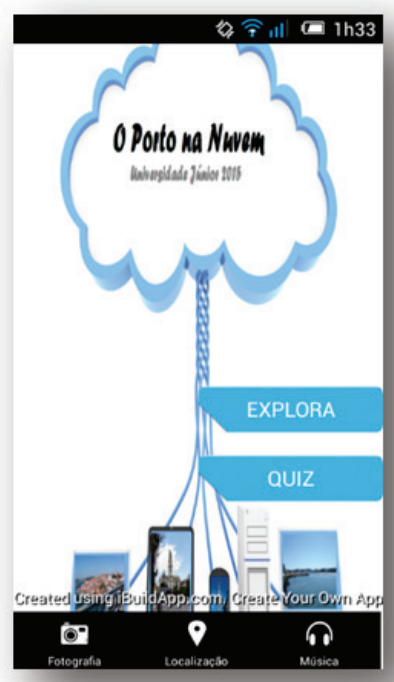

Os restantes botões fornecem informação suplementar, caso da meteorologia, glossário ou, em ambas as apps, a localização de cada um dos monumentos a visitar nas atividades, bem como ferramentas complementares, caso do leitor de códigos $Q R$ e da máquina fotográfica. 


\section{A aplicação "VêsTudo"}

A aplicação "VêsTudo" foi explorada numa visita de estudo realizada no âmbito da disciplina de História A ao património românico do Vale do Tâmega e Sousa, nomeadamente aos mosteiros de Cête, Paço de Sousa, Travanca e Ferreira, organizada para três turmas do $10^{\circ}$ ano do Curso Científico-Humanístico de Ciências Sociais e Humanas.

Visto que as turmas presentes na visita não eram acompanhadas pelo mesmo professor, resolveu-se que a melhor forma de evitar prováveis constrangimentos referentes a um possível desconhecimento sobre os conteúdos temáticos a abordar na visita, dentro do menu "Monumentos", seria colocar cinco submenus, apresentados na Figura 3.

Figura 3 - Menu Monumentos, app "VêsTudo"

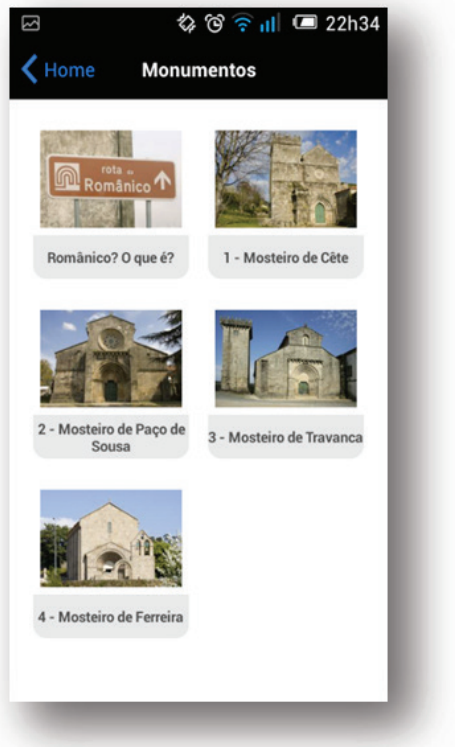

O primeiro exibia um enquadramento sobre o que é a arte românica e a forma como chegou a Portugal, apresentando exemplos dos principais monumentos portugueses e europeus. Os restantes quatro pontos continham informação sobre a história e as características arquitetónicas relevantes, bem como uma galeria fotográfica sobre os mosteiros que seriam visitados, alertando os alunos para os elementos-chave dos edifícios. Concomitantemente, permitiam 
que os alunos, posteriormente, pudessem relembrar a visita por meio das imagens e das descrições cedidas.

A ordem como a informação foi colocada relacionou-se com o trajeto da visita, preparando os alunos para o questionário avaliativo, elaborado na ferramenta Google Forms, embutido na app (Figura 4) instalada em trinta dispositivos Android dos alunos, agrupado consoante os textos de apoio e o roteiro disponibilizados.

Figura 4 - Guião de exploração

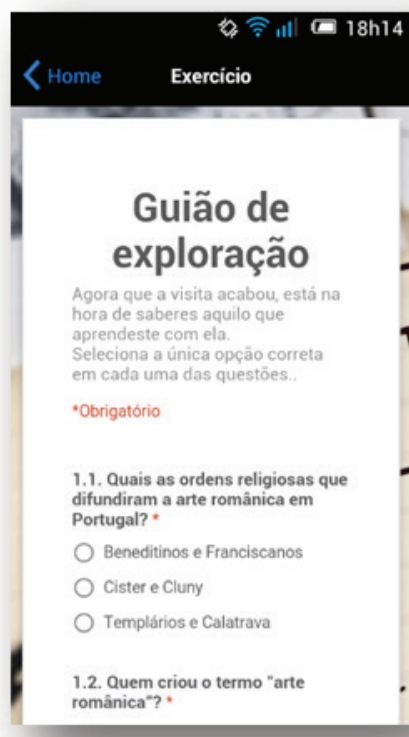

A realização deste exercício foi o único momento em que se necessitou de acesso à internet. Para isso, os professores responsáveis forneceram uma ligação banda-larga, eliminando qualquer constrangimento para os alunos.

Esse exercício, composto por 52 questões de escolha múltipla, contemplou os dados cedidos na app, bem como informações que tanto o Técnico Intérprete do Património como os professores acompanhantes na visita forneceram aquando da visita.

A realização da avaliação aconteceu no final da visita (antes do regresso ao recinto escolar), em trabalho de pares, abrangendo um total de 60 alunos, 
dois por aplicação instalada. Essa tarefa relembrou os alunos, tentados a pensar que estavam num passeio, que afinal estavam numa visita de estudo, "um processo faseado, envolvendo a preparação prévia na aula, a concretização de várias tarefas no local e o tratamento da informação recolhida”, como referem Galvão, Reis, Freire e Oliveira (2006).

Com os resultados obtidos (automaticamente disponibilizados graficamente pela plataforma Google Drive), avaliados consoante a classificação oficial para trabalhos da Escola Secundária de Paredes, o professor poderia comprovar a eficácia da visita e, em simultâneo, verificar com grande facilidade onde se encontravam as maiores dificuldades, permitindo que preparasse as aulas seguintes de acordo com as debilidades registadas.

A cada uma das 52 questões atribuiu-se o valor igualitário de 1,92 ponto, resultando num total de 100 pontos percentuais.

Analisando os resultados, no geral podemos considerá-los como razoáveis, visto que $60 \%$ dos grupos obtiveram classificação positiva: 17 atingiram o nível Suficiente, 1 o nível Bom e os restantes 12 não passaram do Insuficiente (Tabela 1).

Tabela 1 - Classificação por grupo

\begin{tabular}{c|c}
\hline Fraco $(0-19 \%)$ & 0 \\
\hline Insuficiente (20 a 49\%) & 12 \\
\hline Suficiente (50 a 69\%) & 17 \\
\hline Bom (70 a 89\%) & 1 \\
\hline Muito Bom (90 a 100\%) & 0 \\
\hline
\end{tabular}

A rigidez imposta por esse tipo de avaliação, baseado em respostas fechadas, de escolha múltipla, no qual o aluno ou seleciona a resposta correta, ou não lhe será atribuída pontuação, impede a valorização de uma ideia ou um argumento que apresente, barrando a possibilidade de obter pontos que proporcionem a transição para uma classificação superior.

Os resultados obtidos na avaliação da atividade e as informações recolhidas ao longo da visita - onde a curiosidade, a motivação e as intervenções dos alunos demonstraram que recorreram várias vezes à $a p p$ durante a visita, observando com um inegável interesse os monumentos que sempre os rodearam - demonstram que as novas tecnologias de mobile learning podem contribuir 
para o desenvolvimento da consciência histórica e mais especificamente para a consciência da necessidade de preservação e valorização do património arquitetónico local.

\section{A aplicação "O Porto na Nuvem"}

A aplicação "O Porto na Nuvem" foi utilizada numa atividade de verão com o mesmo nome, promovida pela Universidade Júnior 2015, que é considerada o maior programa nacional de iniciação ao ambiente universitário para os estudantes do ensino básico ( $2^{\circ}$ e $3^{\circ}$ ciclos) e secundário.

O objetivo prendia-se com o desenvolvimento da consciência histórica dos jovens, tomando novamente como ponto de partida e referência o património local da cidade do Porto, tal como: Jardim da Cordoaria, estátua de Camilo Castelo Branco, Centro Português da Fotografia, Igreja dos Clérigos, Estação de Porto São Bento, Ardina e estátuas de D. Pedro I e Almeida Garrett - (Figura 5), bem como entender qual a visão dos “juniores” sobre estes, mediante fotografias capturadas por eles mesmos com dispositivos móveis.

Figura 5 - Pontos de Visita

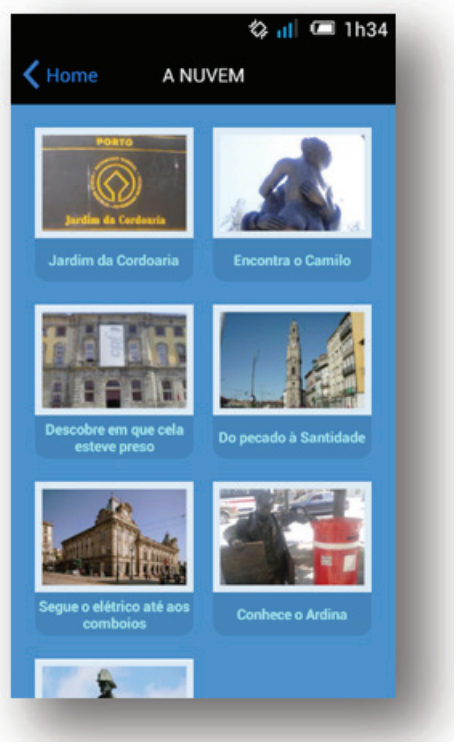


A atividade desenvolveu-se ao longo de quatro semanas e, todos os dias, o grupo de crianças variava, portanto, era necessário perceber o que conheciam antes de iniciar a visita, adotando uma metodologia que permitisse a exploração mais efetiva da atividade, proporcionando uma experiência de qualidade. Rapidamente se percebeu que o trabalho em grupo, dividindo os juniores pelos monitores, seria o melhor método pois, além de facilitar o controlo da atividade, gerava uma ligeira competição entre os grupos, algo que as crianças dessa idade veem com particular entusiasmo.

Desse modo, diariamente, eram criados dois grupos com 6 ou 7 elementos (consoante o número de participantes), cada um acompanhado por um monitor que disponibilizava um tablet munido com a app "O Porto na Nuvem", usando-o como instrumento auxiliar da visita aos monumentos, tanto para a sua exploração, como para a sua avaliação mediante um quiz. O dispositivo também servia para a recolha fotográfica (através da sua câmara) que, numa última fase, seria utilizada para criar uma série de apresentações, em formato PowerPoint, que retratassem a visita.

Assim, além da apresentação de cada um dos locais, feita pelos próprios jovens, apoiados pelos conteúdos disponibilizados na app, propunha-se uma série de desafios especificamente criados para cada um dos pontos da visita, que ajudasse a assimilar os conhecimentos adquiridos sem descurar o divertimento que uma atividade de férias de verão deve ter. Esses desafios contemplavam desde a descoberta de momentos marcantes da história da cidade à captura de selfies, da caça à estátua até à realização de quadros vivos, sempre com vista à aquisição de conhecimentos necessários para responder ao quiz realizado como avaliação diária da atividade e, em última análise, para o desenvolvimento da sua consciência histórica relativa à necessidade de valorização do património local da cidade do Porto.

O quiz, composto por 29 questões, foi construído com base na informação disponibilizada na aplicação, bem como em características indicadas durante a visita. Visto não ser uma atividade de educação formal, decidiu-se não atribuir uma classificação e, ao invés, fazer uma correção em jeito de concurso, indicando a cada um dos grupos o número de respostas erradas que apresentaram, corrigindo-as de imediato. 
Figura 6 - Submenu Estação de Porto São Bento

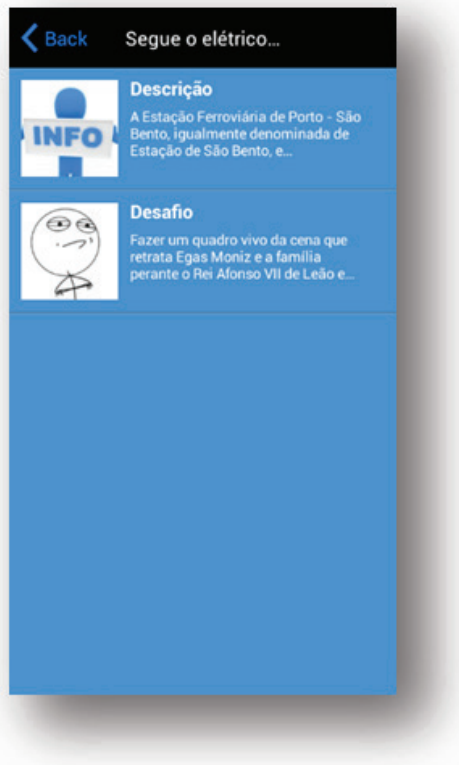

Figura 7 - Quiz"O Porto na Nuvem”

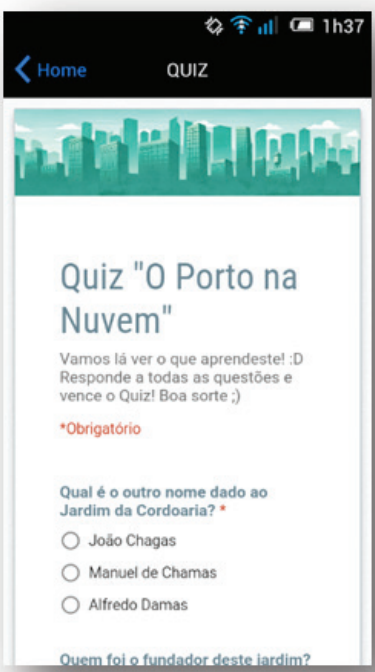


Ao analisarmos os resultados verificamos que os jovens estiveram bastante atentos e interessados ao longo da realização das atividades pois, no geral, o número de respostas erradas no total dos questionários foi bastante reduzido, normalmente entre 0 e 2 respostas erradas, como podemos verificar no Gráfico 1.

\section{Gráfico 1 - Resultados do quiz por número de respostas erradas}

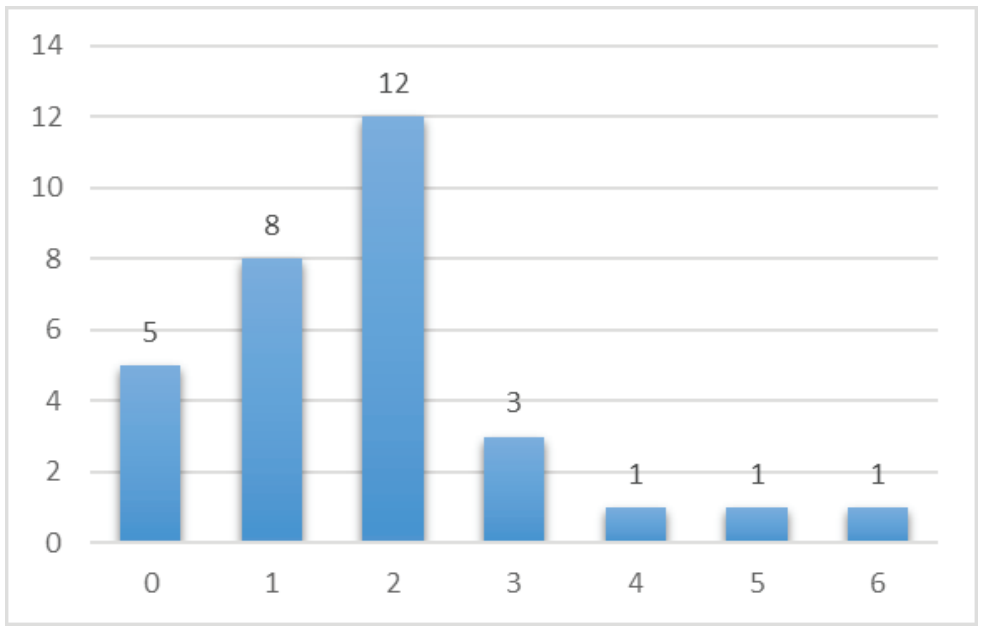

A maioria das questões obteve $100 \%$ das respostas corretas, respeitantes aos elementos visíveis na própria visita, mencionados nos desafios apresentados na app. Quanto às questões erradas, além dos habituais erros com identificação de figuras históricas e a sua respetiva localização temporal, a grande maioria, na opinião dos monitores, derivou de distração.

Atentando nos resultados obtidos no quiz e nas reações recolhidas aquando da realização das atividades, consideramos que a utilização da aplicação "O Porto na Nuvem" foi bastante positiva. Os jovens estão habituados a usar seus dispositivos móveis (tablets e smartphones) com outros fins que não o educativo, e, quando promovemos esse tipo de utilização, mostram-se curiosos, interessados e, principalmente, motivados para explorar e desenvolver a sua consciência histórica e o conhecimento do património que os rodeia, mesmo quando este se insere em locais e monumentos que façam parte do seu quotidiano. 


\section{Conclusões}

Os dois estudos de caso apresentados, desenvolvidos e analisados com o intuito de perceber o alcance que a utilização de estratégias de mobile learning poderia ter junto de alunos no âmbito da sua educação histórica e do desenvolvimento da consciência histórica, permitem retirar-se várias ilações.

A primeira prende-se com a confirmação da realidade atual de que os alunos de hoje estão de facto familiarizados com as novas tecnologias móveis, mas não estão habituados a percebê-las como instrumentos de aprendizagem. A utilização de aplicações móveis como instrumentos de ensino-aprendizagem constitui-se como uma atividade inovadora para a maior parte dos alunos que participaram nas duas experiências didáticas e revelou um grande potencial motivador, na medida em que os jovens se mostraram permanentemente envolvidos na atividade, curiosos e surpreendidos pela possibilidade de usarem objetos (tablets e smartphones) geralmente interditos no processo de ensino-aprendizagem em contexto de sala de aula.

Além disso, verificou-se que, efetivamente, os dispositivos móveis podem contribuir para o desenvolvimento da consciência histórica, na medida em que fornecem acesso a um vasto conjunto de informações, previamente selecionadas pelo professor ou não, que depois pode ser alvo de análise crítica por parte dos alunos. Nos dois estudos de caso apresentados o elemento central de exploração foi o património local de duas regiões distintas. Ao longo das atividades desenvolvidas com o recurso aos dispositivos móveis, os alunos não ficaram apenas a conhecer a história dos espaços percorridos. Perceberam que são relatos do passado que fazem parte igualmente do seu quotidiano e, como tal, devem ser preservados e salvaguardados pelo seu valor histórico e cultural.

Em simultâneo, verificou-se ainda que os dispositivos móveis e as aplicações móveis podem ser excelentes recursos para a dinamização de visitas de estudo. Em primeiro lugar, porque podem ser objetos de pesquisa leves e fáceis de transportar, contendo todo um conjunto de informações complementares que ajuda a compreender melhor o que é visto no terreno e, nesse sentido, são bons recursos de integração e contextualização de conhecimentos. Ao mesmo tempo, podem conter um conjunto de atividades a realizar ao longo da visita, desmistificando a ideia de que uma visita de estudo é um "passeio" que permite 
a saída da sala de aula, consciencializando os alunos de que realmente estão a aprender, mas num espaço físico diferente do habitual. O mobile learning adquire aqui um duplo sentido pois não são apenas os dispositivos que são móveis, mas os próprios alunos são móveis, podendo deslocar-se de um local para o outro, mantendo a sua aprendizagem verdadeiramente ativa.

Porém, é importante ressalvar que a utilização de aplicações móveis em contexto de ensino e de aprendizagem em visitas de estudo deve ser cuidadosamente pensada e previamente preparada. Não será sempre necessário que o professor construa as suas próprias aplicações móveis, embora o possa fazer, mas sobretudo deverá ter a capacidade de explorar as múltiplas aplicações online que hoje estão ao seu dispor e que, na maior parte das vezes, já são do conhecimento dos alunos. Cabe sempre ao professor a capacidade de fazer seus alunos perceberem que os dispositivos móveis servem para mais do que comunicar com os amigos e familiares, são mais do que instrumentos lúdicos e se podem constituir também como instrumentos de aprendizagem.

Para ter uma maior monitorização das atividades que os alunos realizam e das suas aprendizagens, o professor pode recorrer ainda a questionários online, que se constituem como um bom método de recolha de informação sobre a aprendizagem dos alunos e de sua avaliação. Estes apresentam ainda uma dupla vantagem que se prende novamente com o seu carácter motivador. $\mathrm{O}$ facto de poderem utilizar o seu próprio dispositivo móvel na realização do questionário desprende a atividade de avaliação do seu carater rígido e formal. Nos dois estudos de caso, muitas vezes os alunos viram os questionários quase como um jogo, aos quais respondiam empenhadamente.

Além disso, estes estudos de caso desmistificam ainda a ideia de que o uso de dispositivos móveis em contexto de aprendizagem constitui um fator de distração e desinteresse dos alunos. Pelo contrário, revelaram-se recursos altamente motivadores que recentraram a atenção do aluno na aprendizagem. Ao mesmo tempo, permite-lhes o acesso a uma quantidade de informação infindável, que os obriga a fazer uso do seu sentido crítico. No caso do ensino da História, essa realidade reflete-se no desenvolvimento da consciência histórica e sobretudo na possibilidade de preparar os alunos para os desafios do mundo atual, ensinando-os não só a rentabilizar todas as potencialidades das novas tecnologias, mas também a selecionar a informação que lhes é constantemente dada e que tem, obrigatoriamente, de ser pensada e analisada de forma crítica. 


\section{REFERÊNCIAS}

BARCA, Isabel. Literacia e consciência histórica. 2008. Disponível em: http://ojs.c3sl. ufpr.br/ojs2/index.php/educar/article/view/5545; Acesso em: 27 mar. 2016.

FERREIRA, Cristiano. "App(lica-te)": As novas tecnologias como suporte às visitas de estudo. Relatório de Estágio. Faculdade de Letras da Universidade do Porto. Porto, 2015.

GALVÃO, Cecilia; REIS, Pedro; FREIRE, Ana; OLIVEIRA, Teresa. Avaliação de competências em educação. Porto: Ed. ASA, 2006.

GUERREIRO, Sara Isabel A. G. L. A utilização das novas tecnologias enquanto estratégia facilitadora do processo ensino-aprendizagem. Relatório de Estágio. Faculdade de Letras da Universidade de Coimbra. Coimbra, 2013.

KUKULSKA-HULME, Agnes. Current Uses of Wireless and Mobile Learning: Landscape Study Wireless and Mobile Learning in the post-16 sector. JISC e-Learning Programme. 2005. Disponível em: http://www.jisc.ac.uk/uploaded_documents/ Current\%20Uses\%20FINAL\%202005.doc; Acesso em: 27 mar. 2016.

METCALF, David S. Stolen moments for learning. eLearning developers' Journal. 2002. Disponível em: http://www.elearningguild.com/articles/abstracts/index. cfm?id=52\&action=viewonly; Acesso em: 27 mar. 2016.

MOREIRA, Carla. O entendimento do património no contexto local. Oppidum, n.1, p.127-140, 2006. Disponível em: http://www.rotadoromanico.com/SiteCollectionDocuments/Romanico_Mais\%20Informacao/Revista\%20OPPIDUM/O_entendimento_do_Patrim\%C3\%B3nio_no_contexto_local_pp.127-140.pdf

MOREIRA, Maria da Graça. Conexão e mobilidade: o currículo na cultura digital. 2013. Disponível em: http://eadconsultoria.moodlelivre.com/file.php/1/palestras/ ArtigoCurriculoCultura.pdf; Acesso em: 3 set. 2015.

MOURA, Adelina Maria C. Apropriação do telemóvel como ferramenta de mediação em Mobile Learning: estudos de caso em contexto educativo . Tese (Doutoramento) - Universidade do Minho. Braga, 2010.

SHARPLES, Mike. Towards a Theory of Mobile Learning. Proceedings of mLearning. 2005. Disponível em: http://mlearning.noekaleidoscope.org/public/mlearn2005/ www.mlearn.org.za/CD/papers/Sharples-\%20Theory\%20of\%20Mobile.pdf; Acesso em: 27 mar. 2016.

TRINDADE, Sara Marisa G. D. do C. O passado na ponta dos dedos: o mobile learning no ensino da História no $3^{\circ}$ Ciclo do Ensino Básico e no Ensino Secundário. Tese (Doutoramento) - Universidade de Coimbra. Coimbra, 2014.

Artigo recebido em 2 de abril de 2016. Aprovado em 10 de maio de 2016. 